\title{
Knowledge and Attitude of Low-Literacy Patients Undergoing Suprapubic Catheter Insertion
}

\author{
Rasha Abozead Khalaf ${ }^{1}$, Rabea Ahmed Gadelkareem ${ }^{2}$, Shalabia El-Sayed Abozead ${ }^{3}$, Shaymaa Sayed Khalil ${ }^{4}$ \\ ${ }^{1 .}$ BSc. Medical-Surgical Nursing Faculty of Nursing, Assiut university, Egypt. \\ 2. Assistant Professor of Urology,Faculty of Medicine, Assiut University, Egypt. \\ 3. Professor of Medical-Surgical Nursing, Faculty of Nursing, Assiut University, Egypt. \\ 4. Lecturer of Medical-Surgical Nursing, Faculty of Nursing, Assiut University, Egypt.
}

\begin{abstract}
:
Background: Providing the patient with sufficient knowledge about his illness improves the outcomes when delivered properly. Aims: To assess the knowledge and attitude of low-literacy patients undergoing suprapubic catheter insertion. Methods: Study design: Descriptive research design was utilized. Setting: Urology and Nephrology Hospital, Assiut University. Subjects: Eighty patients undergoing suprapubic catheter were selected consecutively within a 12-month period (with maximally primary school educations). Tools: Patient interview questionnaire included 4 parts; parts 1 and 2 to assess demographic and medical data, parts 3 and 4 to assess patients' level of knowledge and attitude. Results: All patients were males with $47.5 \%$ of them aged from 50-65 years old. They had poor knowledge about the indications $(0 \%)$, definition $(0 \%)$, function $(6.3 \%)$, procedures of insertion $(2.5 \%)$ and change $(22.5 \%)$, receipt of education at the primary care settings $(47.5 \%)$, ability of self-healthcare $(40 \%)$, previous experiences $(10 \%)$ postoperative symptoms $(0 \%)$ and complications among the studied patients $(17.5 \%)$ including urine leakage $(8.7 \%)$ and obstruction $(17.5 \%)$ of the suprapubic catheter. While most of the patients $(95 \%)$ reported insufficient healthcare education at the primary settings, all the studied patients wished to have a suitable method for education. There was no statistically significant relation between total knowledge levels and the demographic data. Conclusions: Most of the patients had poor knowledge about the suprapubic catheter and favorable attitudes towards suitable education. Recommendations: Designing a simple method to provide healthcare education for low-literacy patients undergoing suprapubic catheter.
\end{abstract}

\section{Keywords: Healthcare education, Patient knowledge \& Suprapubic catheter.}

\section{Introduction:}

Suprapubic catheter (SPC) is a device for drainage of the urinary bladder in cases of unsuitable or contraindicated urethral catheterization. Many indications have been reported under different categories including relief of acute urinary retention, management of urinary incontinence in cases of neurogenic bladder, and urinary diversion in the perioperative period and for immobilized patients. SPC is inserted into the bladder less than two fingerbreadths above the pubic bone, either percutaneously or by open surgery. It is a relatively common and simple procedure in the daily urological practice, but it has many complications (Hall et al., 2020; Serlin et al., 2018).

As a urinary catheter, SPC needs a suitable healthcare education of the patients to avoid the postoperative complications and this is the duty of the nurse who should translate medical and technical knowledge into a simple and useful guidance for this group of patients (Hall et al., 2020). Patients' healthcare education is a set of guidelines or techniques that increase the awareness toward their disease and get useful of them. It is important to the patient and his family to learn as much as he can about the disease, its symptoms, how it may progress and what treatment options are available. The education helps patients to acquire sufficient knowledge to take shared informed decisions and choose the type of care that provide them with the most benefits (Kingod et al., 2017). There are many methods to educate the patients about their illnesses. To choose a suitable healthcare education method from the available options, it is imperative to know the literacy level of the targeted population. On the other hand, SPC is commonly performed in adults and elderly males who may have insufficient knowledge and capabilities to manage SPC and its potential complications properly (English, 2017). These considerations represented our rationale to know the knowledge and attitude of the patients undergoing SPC insertion.

\section{Significance of the study:}

From their clinical experience at the Urology Department, the researchers observed that patients may get many complications after SPC insertion. This observation may refer to that those patients may do not have enough knowledge regarding the postoperative care of SPC. So, standing on the level 
of their knowledge about SPC may help in developing a suitable tool for improving the outcomes that are based on their education.

Aims of the study:

To assess knowledge and attitude of low-literacy patients undergoing suprapubic catheter insertion.

Research Questions:

1. What is the patients' knowledge level regarding SPC?

2. Do the patients have the suitable knowledge about SPC?

3. What is the attitude of those patients towards the healthcare education at their primary and tertiary healthcare settings?

\section{Patients \& Methods:}

\section{Research design:}

Descriptive research design was utilized in this study. Study setting:

This study was conducted at the Urology and Nephrology Hospital, Assiut University, Assiut, Egypt, during the period from September 2019 to August 2020

Study sample:

A total number of 80 patients participated in this study within 12 months. This sample size was calculated using the equation described by Thompson (2012):

$$
n=\llbracket \frac{N \times p(1-p)}{\left.\left.\llbracket N-1 \times\left(d^{2} \div z^{2}\right)\right]+p(1-p)\right]}
$$

Where $\mathrm{N}=$ total patient population size of 106 patients who admitted to insert SPC at the Urology and Nephrology Hospital during the years 2016-2018. By $\mathrm{n}=100, \mathrm{z}=$ confidence level is 0.95 and is equal to $1.96, \mathrm{~d}=$ The error ratio is 0.05 , and $\mathrm{p}=$ The property availability ratio and neutral $=0.50$.

Patient selection criteria:

From the adult patients who were undergoing percutaneous SPC, we excluded patients with secondary school education levels or higher, age of less than 18 or more than 65 years old, inability to perceive or respond to the questionnaire, and/or patients who refused to participate in the study.

\section{Tools of data collection:}

Data were collected through a Patients' interview questionnaire (researcher-filled) consisting of 4 parts:

Part (I): Patients' demographic characteristics assessment: Patient's age, sex, level of education, and occupation.

Part (II): Patients' clinical characteristics assessment: Primary medical diagnosis, main presenting symptoms, associated systematic diseases, hemodynamic parameters, and length of hospital stay. Part (III): Patients' level of knowledge assessment: This part consisted of 12 questions to assess patients' level of knowledge about SPC indications, definition, function, procedures of insertion and change. As well, it included questions asked about patients' previous experiences, selfhealthcare capabilities, postoperative symptoms and complications of SPC.

Part (IV): Assessment of patients' attitude towards the healthcare education at primary and tertiary settings: Patients were asked about the attitude towards the previous healthcare education at the primary care facilities and the suitability of healthcare education at our hospital in two separate questions.

The scoring system for knowledge and attitude parts: The total score was 12 degrees; 1 point was given for each correct answer, while each incorrect answer was given Zero point. The total knowledge score was classified into: Good knowledge level ( $\geq 75 \%$ of the total score), fair knowledge level (from 50 to $<75 \%$ ), and poor knowledge level $(<50 \%)$. This scoring was adapted from the previous similar studies (Onianwa et al., 2017). The attitude questions were considered separately and scored as positive or negative (agreed or disagreed).

\section{Ethical considerations:}

Research proposal was approved from Ethical Committee in the Faculty of Nursing, Assiut University. There was no risk for patients during application of the research tool. The study followed the common ethical principles in the clinical research, according to the declaration of Helsinki (World Medical Association, 2013). Informed consent was obtained from the patients after explaining the nature and purpose of the study. Confidentiality and anonymity were assured. Study patients had the right to refuse to participate and/or withdraw from the study without any rational at any time. Also, their privacy was considered during collection of data. An official permission was obtained from the dean of the Faculty of Nursing, Assiut University and the chairman of the Urology Department, Assiut University.

\section{Tools Validity and Reliability:}

It was established by a panel of three expert staff in nursing ( 2 professors) and medicine (1 professor) who reviewed the instruments for its clarity, relevance, comprehensiveness, understanding, applicability, and easiness for administration. Then, minor modifications were required. Test reliability of the proposed tool was ascertained with Cronbach's alpha $=0.86$. 


\section{Pilot study:}

A pilot study was conducted on 10 patients from the selected setting to evaluate the applicability and clarity of the developed tool and estimated time needed to answer the questionnaire. No necessary changes were done. So, the patients who were selected for this pilot study were included in the main study also.

\section{Statistical design:}

The collected data were tabulated and statistically analyzed to estimate the outcomes in regard to the various variables. The statistical analysis was done using computer program SPSS version 23. Descriptive statistics (number, percentage, mean \pm SD) were done. Chi-square test was used to compare between qualitative variables. For independent samples, t-test was done to compare between quantitative variables. $P$. value was significant, if it was $<0.05$.

\section{Results:}

Among 128 patients who had indications of SPC insertion at Assiut Urology and Nephrology Hospital during the study duration, 93 patients were eligible to fill the questionnaire. Of them, 80 patients agreed to participate and completed the questionnaire.

Table (1): Frequency distribution of the studied patients' demographic characteristics $(n=80)$.

\begin{tabular}{|l|c|}
\hline \multicolumn{1}{|c|}{ Characteristics } & Number of patients (n=80) \\
\hline Age ( years) & $48 \pm 17.5$ \\
\hline Mean \pm SD & $10(12.5 \%)$ \\
\hline $18-<30$ & $32(40 \%)$ \\
\hline $30-<50$ & $38(47.5 \%)$ \\
\hline $50-65$ & $80(100 \%)$ \\
\hline Sex & $0(0.0 \%)$ \\
\hline Male & \\
\hline Female & $24(30 \%)$ \\
\hline Level of education & $44(55 \%)$ \\
\hline Not educated & $12(15 \%)$ \\
\hline Read and write & $36(45 \%)$ \\
\hline Primary & $44(55 \%)$ \\
\hline Occupational Status & \\
\hline Work & \\
\hline Not work & \\
\hline
\end{tabular}

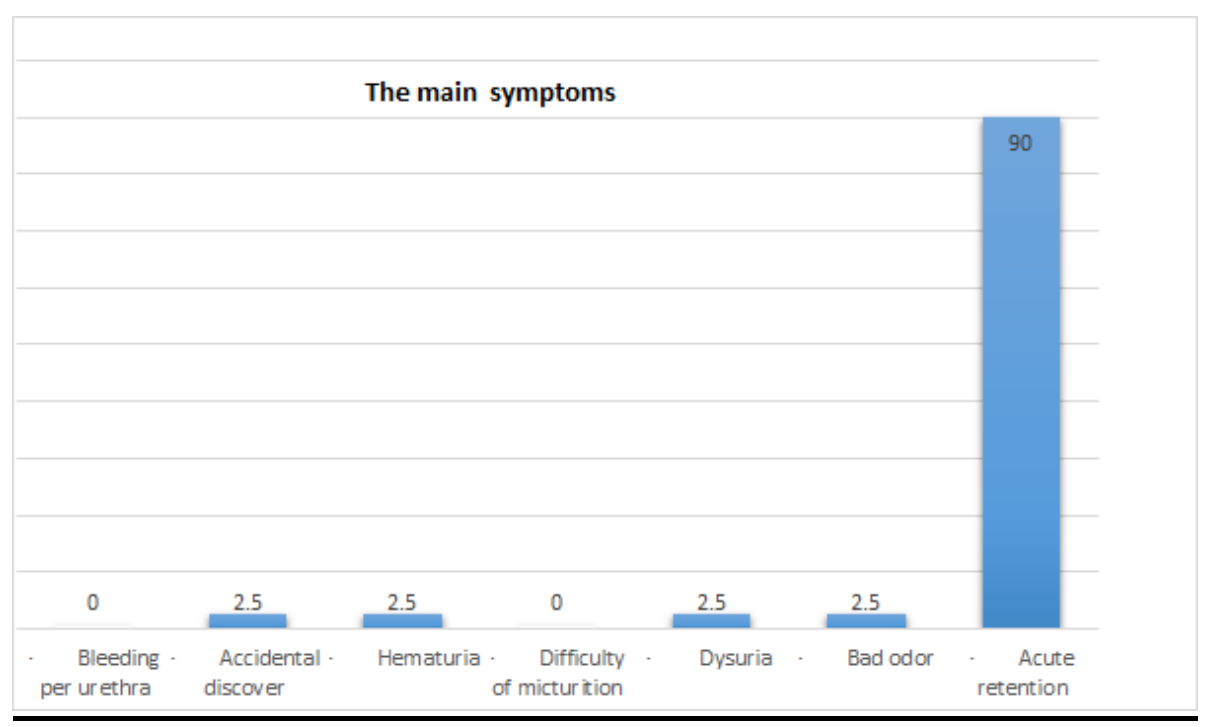

Figure (1): The studied patients' main presentation symptom $(n=80)$. 


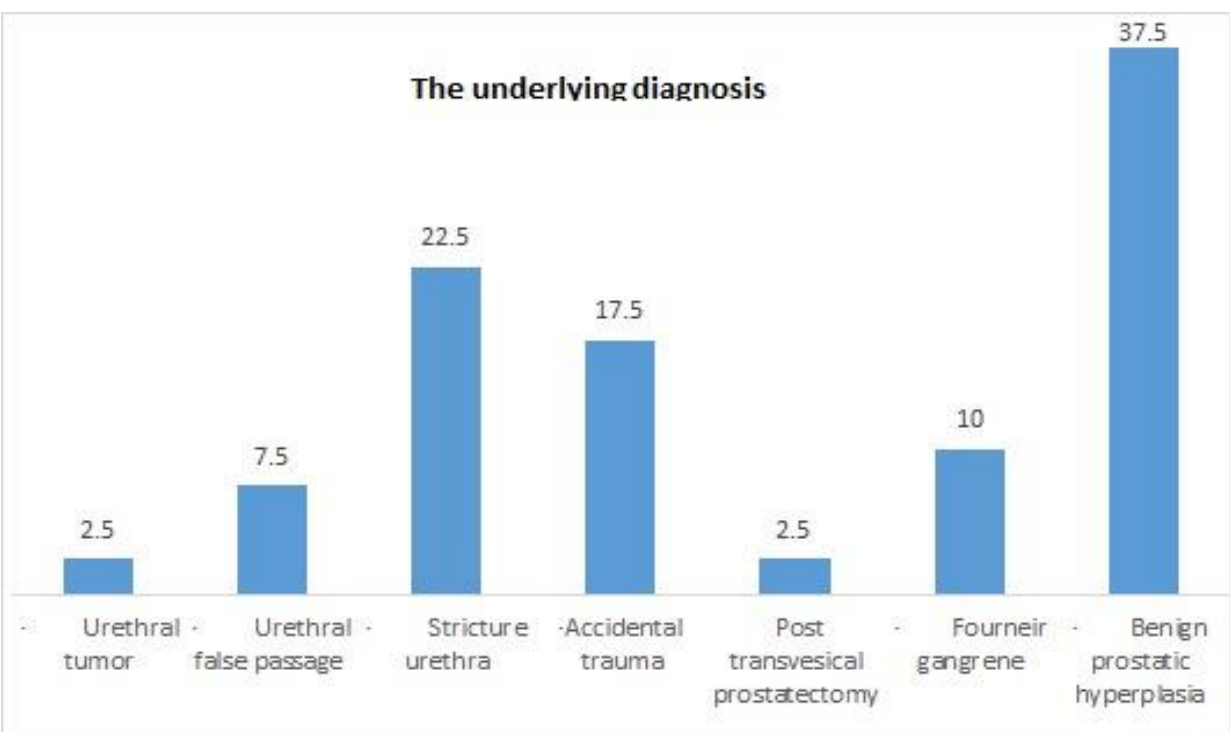

Figure (2): Distribution of studied sample primary diagnosis during admission ( $n=80)$.

Table (2): Patients' level of knowledge about SPC ( $N=80)$

\begin{tabular}{|l|c|c|}
\hline \multicolumn{1}{|c|}{ Knowledge items about SPC } & \multicolumn{2}{c|}{ Patients (n=80) } \\
\cline { 2 - 3 } \multicolumn{1}{|c|}{} & Correct knowledge & Incorrect knowledge \\
\hline Medical diagnosis/Indication & $0(0.0 \%)$ & $80(100 \%)$ \\
\hline Definition & $0(0.0 \%)$ & $80(100 \%)$ \\
\hline Function & $5(6.3 \%)$ & $75(93.7 \%)$ \\
\hline Procedure of insertion & $2(2.5 \%)$ & $78(97.5 \%)$ \\
\hline Change & $18(22.5 \%)$ & $62(77.5 \%)$ \\
\hline Knowledge from primary care setting & $38(47.5 \%)$ & $42(52.5 \%)$ \\
\hline Self-healthcare capabilities & $32(40 \%)$ & $48(60 \%)$ \\
\hline Postoperative symptoms & $0(0.0 \%)$ & $80(100 \%)$ \\
\hline Complications & $14(17.5 \%)$ & $66(82.5 \%)$ \\
\hline Previous experiences & $8(10 \%)$ & $72(90 \%)$ \\
\hline How to avoid urinary leakage & $7(8.7 \%)$ & $73(91.3 \%)$ \\
\hline What to do with blockage & $14(17.5 \%)$ & $66(82.5 \%)$ \\
\hline
\end{tabular}

Table (3): Patients' attitude about healthcare education about suprapubic catheter at the primary and tertiary healthcare settings $(\mathrm{N}=80)$

\begin{tabular}{|c|l|c|c|}
\hline \multicolumn{2}{|c|}{ Attitude items of healthcare education about suprapubic catheter } & \multicolumn{2}{|c|}{ Patients (n=80) } \\
\cline { 2 - 4 } $\begin{array}{c}\text { Healthcare education at } \\
\text { primary healthcare settings }\end{array}$ & Suitability & $6(7.5 \%)$ & $74(92.5 \%)$ \\
\cline { 2 - 4 } & Sufficiency & $4(5 \%)$ & $76(95 \%)$ \\
\hline \multirow{2}{*}{\begin{tabular}{c} 
Healthcare education at our $\begin{array}{c}\text { settings } \\
\text { setred }\end{array}$ \\
\cline { 2 - 4 }
\end{tabular}} & Interests & $80(100 \%)$ & $0(0 \%)$ \\
\cline { 2 - 4 } & It will be beneficial & $73(91.25 \%)$ & $7(8.75 \%)$ \\
\hline
\end{tabular}




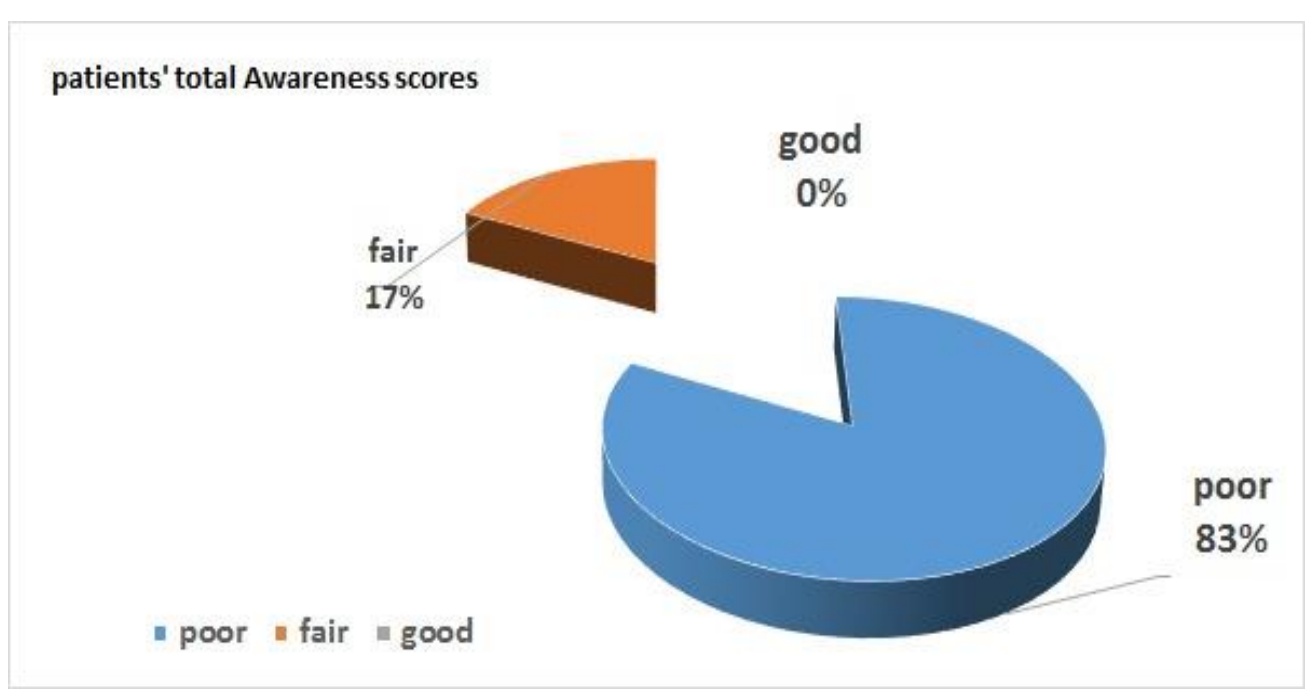

Figure (3): Distributions of the studied patients according to their knowledge level about suprapubic catheter $(\mathbf{n}=\mathbf{8 0})$

Table (4): The relation between total knowledge level and demographic characteristics among the studied patients $(\mathbf{n}=80)$

\begin{tabular}{|c|c|c|c|}
\hline \multirow[b]{2}{*}{ Demographic characteristics } & \multicolumn{2}{|c|}{ Total knowledge level $(n=80)$} & \multirow[b]{2}{*}{ P. value } \\
\hline & $\begin{array}{c}\text { Fair level } \\
(n=14)\end{array}$ & Poor level $(n=66)$ & \\
\hline \multicolumn{3}{|l|}{ Age groups (years) } & \multirow{4}{*}{0.793} \\
\hline $18-<30$ & $2(2.5 \%)$ & $8(10 \%)$ & \\
\hline $30-<50$ & $4(5 \%)$ & $28(35 \%)$ & \\
\hline $50-65$ & $8(10 \%)$ & $30(37.5 \%)$ & \\
\hline \multicolumn{3}{|l|}{ Level of education } & \multirow{4}{*}{0.417} \\
\hline Not educated & $2(2.5 \%)$ & $22(27.5 \%)$ & \\
\hline Read and write & $8(10 \%)$ & $36(5.5 \%)$ & \\
\hline Primary & $4(5 \%)$ & $8(10 \%)$ & \\
\hline \multicolumn{3}{|l|}{ Occupational status } & \multirow{3}{*}{0.130} \\
\hline Work & $10(12.5 \%)$ & $26(32.5 \%)$ & \\
\hline Not work & $4(5 \%)$ & $40(50 \%)$ & \\
\hline
\end{tabular}

Table (1): Showed that approximately half $(47.5 \%)$ of the studied patients' age was from 50 to 65 years.

Figure (1): This figure showed that most of the patients $(90 \%)$ presented with acute urinary retention. Figure (2): This figure shows that the main primary patients' diagnosis during admission was benign prostatic hyperplasia (BPH).

Table (2): This table shows that most of the studied patients had inadequate knowledge regarding the status of each item of the questionnaire that measure patient's level of knowledge about SPC.

Table (3): Regarding the attitude of the patients towards healthcare education about SPC, the majority $(95 \%)$ of the studied patients expressed that the delivered healthcare education to them were insufficient at the primary healthcare settings. Also, all the patients (100\%) wished to have further simplified healthcare education method about SPC.

Figure (3): This figure shows that most of the patients $(83 \%)$ had a poor level of knowledge regarding suprapubic catheter and its symptoms.

Table (4): This table reveled that there was no statistically significant relation between the studied patients' total knowledge level and their demographic characteristics.

\section{Discussion:}

The assignment of the most effective method of urinary bladder drainage from the available routes for a certain patient mandates a thorough assessment and 
tailored decision. The available routes of catheterization include urethral, suprapubic, intermittent or Mitrofanoff. Although urethral catheterization is simple, SPC is a preferred alternative route. However, SPC requires surgical skills for the initial insertion procedure and familiarity with change (Hall et al., 2020).

The nursing role in management and care of urinary catheters is significant. It depends on effective healthcare education to improve the outcomes and patient satisfaction. The literature refers to that studying of SPC has been attended in different perspectives towards the targeted population and the underlying pathologies of SPC. SPC has been studied in clinical and surgical perspectives more than the nursing ones (Kidd et al., 2015).

Regarding the demographic characteristic of the studied patient, most of the patients' age was within average adulthood and all of them were males. The highest percentage of the patients was between the age of 50 and 65 years. Despite the difference of age range, our finding was similar to the study done by Muhammad et al., (2018) who stated that patient's mean age was $50.5 \pm 23.3$ years. However, it was not like Naik et al., (2015) who illustrated in their study that two thirds of the patients aged between 40-60 years old and Okorie (2014) who reported a mean age of 61 years. This is due to the nature of the underlying diseases where the prostatic and urethral disorders lead to obstruction in males rather than in females (Zango et al., 2016). This was different from the patients in studies done by Lavelle et al. (2016) and Nagao et al. (2019) who presented higher percentages of female patients due to different underlying diagnoses.

Most of our cases were emergency cases presented by acute urinary retention. Also, the underlying pathologies or diseases are variable and include prostatic enlargement, bladder neck contracture, urethral stricture or trauma, and neurogenic bladder (English, 2017). BPH is a common cause of urinary obstruction among old males (Okorie, 2014). It represented the cardinal cause in the current study which was similar to urethral trauma among those subjects. The most common diagnosis on admission among the studied sample was BPH with acute retention. This was similar to Jian et al., (2018) who suggested that the main diagnoses for SPC were $\mathrm{BPH}$, false urethral passages, morbid obesity, urethral strictures, and urinary retention. At the same line Muhammad et al., (2018) and other studies (Okorie, 2014 \& Zango et al., 2016) reported that the diagnosis of the patients who needed SPC was urethral stricture, $\mathrm{BPH}$, urethral stone and urethral injury.
In the current study, most of the patients had very low literacy skills where the educational levels were just "read and write" or lower. This could be attributed to the patient's selection criteria which was based on the presence of high proportions of those patients among the populations of our locality and similar countries with low-resource facilities (Okorie, 2014 Muhammad et al., 2018 \& Zango et al., 2016).

Based on the analysis of the data collected by the questionnaire used in current study, around half of the patients were unaware about their primary medical diagnosis, function and definition of SPC. Also, the knowledge about the procedure of primary insertion of SPC and the way of change were incorrectly known by most of the studied patients. On the other hand, only less than half of the patients received knowledge or education about SPC at their primary healthcare settings. In developing countries, there is a deficiency in the resources that may hinder the implementation of high-quality surgical and healthcare services to those patients. Usually, there are persistent needs to find alternatives to afford these demands (Okorie, 2014 Muhammad et al., 2018 \& Zango et al., 2016).

Teaching the patients how to take care of an indwelling catheter is a cornerstone factor in improving urinary catheters outcomes (English, 2017 Corder and LaGrange 2020 \& Hall et al., 2020). The results of the current study showed that most of the patients did not know the correct knowledge. This could be attributed to the insufficient educational services at the primary care facilities and their lowliteracy skills (Liu et al., 2020 \& Choi, 2011). Also, when the patients asked about the symptoms and the complications (tube obstruction, hematuria, burning sensation, urine leakage, fever, and abdominal pain) that may result from SPC postoperatively, most of the patient were not aware about what to do with the SPC when it was blocked. Most of the studied patients had poor knowledge about SPC, as most patients were old age and had low-literacy levels. This matches with the recent attitude in the literature about the unfavorable effects of the low-literacy skills on the disease outcomes (Liu et al., 2020). However, Minejima et al. (2019) reported that the patients' characteristics did not correlate with their knowledge about their disease and its management.

The attitude of the patients in the current study was favorable for designing a suitable healthcare education method about SPC. They were not satisfied by the delivered healthcare education at the primary care settings which may reflect the poor quality or, even, the unavailability of such services at their primary location. This was similar to the status in 
other countries of similar population characteristics (Liu et al., 2020 \& Muhammad et al., 2018). Also, the studied patients wished to have a suitable education method to receive sufficient knowledge about SPC. These attitudes were similar to the previously reported one in a study done by Chapple et al., (2015).

\section{Conclusions :}

The studied patients had poor levels of knowledge about all the aspects of SPC including the definition, indications, procedure, change, care, and postoperative complications. Most of those patients showed negative attitudes towards the healthcare education at their primary healthcare levels. Also, all of them expressed a favorable attitude towards the implementation of a simple healthcare education method. Accordingly

\section{Recommendations:}

we recommend that patients with low-literacy skills should be provided with sufficient information about SPC before discharge from the hospital. Also, the method of education should be suitable for their literacy skills such as designing illustrated booklets or brochure to facilitate the delivery of nursing instructions.

\section{References:}

- Chapple A, Prinjha S, \& Feneley R (2015): Comparing transurethral and suprapubic catheterization for long-term bladder drainage: a qualitative study of the patients' perspective. J Wound Ostomy Continence Nurs. Vol. (42), No. (2): Pp. 170-5.

- Choi J (2011): Literature review: using pictographs in discharge instructions for older adults with lowliteracy skills. J Clin Nurs. Vol. (20), No. (21-22): Pp. 2984-2996.

- Corder CJ \& LaGrange CA (2020): Suprapubic bladder catheterization. [Updated 2020 Aug 16]. In: StatPearls [Internet]. Treasure Island (FL): StatPearls Publishing; 2020 Jan-. Available from: https://www.ncbi.nlm.nih.gov/books/NBK482179/. Accessed: October 12, 2020

- English SF (2017): Update on voiding dysfunction managed with suprapubic catheterization. Transl Androl Urol. Vol. (6), No. (Suppl 2): Pp. S180S185.

- Hall SJ, Harrison S, Harding C, Reid S, \& Parkinson R (2020): British Association of Urological Surgeons suprapubic catheter practice guidelines-revised. BJU international, Vol. (126), No. (4): Pp. 416-422.
- Jian Z, Feng S, Chen Y, Wei X, Luo D, Li H, \& Wang K (2018): Suprapubic tube versus urethral catheter drainage after robot-assisted radical prostatectomy: a systematic review and metaanalysis. BMC Urol. Vol. (8), No. (1): Pp 1.

- Kidd E, Stewart F, Kassis N, Hom E, \& Omar MI (2015): Urethral (indwelling or intermittent) or suprapubic routes for short-term catheterization in hospitalised adults. The Cochrane database of systematic reviews, Vol. (12), No. (3): Pp. 45-61.

- Kingod N, Cleal B, Wahlberg A, \& Husted GR (2017): Online peer-to-peer communities in the daily lives of people with chronic illness: a qualitative systematic review. Qualitative Health Research, Vol. (27), No. (1): Pp. 89-99.

- Lavelle RS, Coskun B, Bacsu CD, Gliga LA, Christie AL, \& Lemack GE (2016): Quality of life after suprapubic catheter placement in patients with neurogenic bladder conditions. Neurourolgy and Urodynamics, Vol. (35), No. (7): Pp. 831-5.

- Liu L, Qian X, Chen Z, \& He T (2020): Health literacy and its effect on chronic disease prevention: evidence from China's data. BMC Public Health, Vol. (20), No. (690).

- Minejima E, Lee E, Quach S, Santos N, Lou M, \& Wong-Beringer A (2019): Understanding patient perceptions and attitudes toward urinary tract infections and treatment in a medically underserved population. Journal of the American College of Clinical Pharmacy, Vol. (2), No. (6): Pp. 616-622.

- Muhammad AS, Agwu NP, Abdulwahab-Ahmed A Abdullahi K, \& Mungadi IA (2018): Safety and efficacy of ultrasound-guided percutaneous suprapubic cystostomy in resource-poor setting: A 7-year review. Urol Ann. Vol. (10), No. (1): Pp. 2428.

- Nagao S, Saida Y, Enomoto T, Takahashi A, Higuchi T, Moriyama H, Niituma T, Watanabe M, Asai K, \& Kusachi S (2019): Prospective short-term feasibility study of perioperative suprapubic catheters in laparoscopic colectomy. Asian J Endosc Surg. Vol. (12), No. (1): Pp. 64-68.

- Naik R, Maughan K, Nordin A, Lopes A, Godfrey KA \& Hatem MH (2015): A prospective randomized controlled trial of intermittent selfcatheterization vs. supra-pubic catheterization for postoperative bladder care following radical hysterectomy, Vol. (99), No. (2): Pp. 437-42.

- Okorie CO (2014): Simplified percutaneous large bore suprapubic cystostomy for acute urinary retention-A cost saving procedure. African Journal of Urology, Vol. (20), No. (3): Pp. 132-5. 
- Onianwa PO, Aonge TO, Otegbayo JA, lke EU, Chukura FO, Are OO, Akani O, Ayorinde MO, Dubi 1O, \& Yaya OS (2017): Pain as 5th sign, Impact of pain assessment training program on Nigerian nurses knowledge of pain management, International Nursing and midwifery, Vol. (9), No. (1): Pp. 129-135.

- Serlin DC, Heidelbaugh JJ, \& Stoffel JT, (2018): Urinary Retention in Adults: Evaluation and Initial Management. Am Fam Physician, Vol. (98), No. (8): Pp. 496-503.

- Thompson SK (2012): Sample Size. In Sampling, (eds W.A. Shewhart, S.S. Wilks and S.K. Thompson), $3^{\text {rd }}$ edition Chapter 4, New Jersey, John Wiley \& Sons, Inc.

- World Medical Association (2013): World medical association declaration of Helsinki; Ethical principles for medical research involving human subjects. JAMA, Vol. (310), No. (20): Pp. 21912194.

- Zango B, Kaboré FA, Kaboré M, Kirakoya B, Ky BD, Kabré B, Yameogo CAMKD, Ouattara A, \& Kambou T (2016): Suprapubic cystostomy at Urological Emergency Unit of CHU-YO, Ouagadougou, Burkina Faso: Indications, technique and complications. Open Journal of Urology, Vol. (6), No. (4): Pp. 67-71. 